\title{
Youth clubs' contributions towards promotion of Sexual and Reproductive Health Services in Machinga District, Malawi
}

ALINAFE C. LUSINJE, CHETIMILA PHIRI, PRISCA MAJAWA and ADAMSON S. MUULA*

Department of Public Health, School of Public Health and Family Medicine, College of Medicine, University of Malawi, Blantyre, Malawi

\begin{abstract}
Background: In Malawi more than 50\% of the population are young people less than 24 years old. Adolescents and young people face a lot of sexual and reproductive health (SRH) challenges such as unplanned and early pregnancies, sexually transmitted infections (STIs) including HIV and AIDS and abusive intimate relationships. Provision of SRH services through Youth clubs is one strategy that has potential to contribute to addressing the SRH challenges. We conducted a study in Machinga district, southern Malawi to assess the contributions of youth clubs towards promotion of SRH services.

Methods: A cross sectional study was conducted in 2014 among youths aged $15-24$ years. The participants were drawn from Machinga boma and Liwonde Township. We used both quantitative and qualitative methods. Quantitative data were collected using questionnaires, while Focus Group Discussions (FGDs) and Key informant interviews were used to collect qualitative data. Quantitative data were analysed by estimating proportions and Chi square tests while thematic content analysis was used for qualitative data. The study was approved by University of Malawi's College of Medicine Research and Ethics Committee (COMREC).

Results: Frequently offered services in youth clubs were HIV and AIDS education reported by $48.4 \%$ of the study participants, STI education (16.7\%), family planning(16.7\%) and life skills education (9.7\%). On service utilisation there was no association between attendance to youth clubs and HIV Testing Counselling ( $\chi^{2}$ $=0.76, p=0.4)$ and there was no association between attendance to the youth clubs and family planning utilisation $\left(\chi_{2}=3.1, p=0.3\right.$ ). Condom use was the most used contraceptive method among the study participants. Misconception, accessibility and poor attitude of health workers were some of the factors reported as contributing to low utilisation of family planning methods. All youth club participants, reported by 89 study participants and only $29.4 \%$ of club non-attendees had adequate SRH knowledge. The services provided by health workers to youth clubs reported by study participants were HIV and AIDS education, HIV testing and counselling (HTC) and condom distribution.

Conclusion: Our findings highlight the need of youth clubs to promote SRH services.Efforts should be made to ensure that the identified challenges are dealt with to ensure effective participation of youth
\end{abstract} clubs.

Keywords: sexual, reproductive, HIV and AIDS, youth friendly, health services, Malawi

\section{Introduction}

In Malawi children and young people aged less than 24 years account for more than $50 \%$ of the population. Adolescents and young people face significant challenges in relation to sexual and reproductive health $(\mathrm{SRH})$ such as prevention and acquisition of sexually transmitted infections (STI) including HIV and AIDS, unsafe abortions, consumerism, correct and accurate reproductive health information and accessibility of SRH services in public health facilities (Senderowitz et al, 2003; Levandowski, 2013; Kidman \& Anglewicz, 2014). Fifty four percent of all people accessing post-abortion care in Malawi in 2009 were women aged 24 years and below (Levandowski, 2013).

The United Nations Population Fund (UNFPA) and the population division of the United Nations Department for Economic and Social information and Policy Analysis organised an International Conference on Population and Development (ICPD) which was held in Cairo, Egypt in 1994 (Wentzell \& Inhorn, 2014). The conference acknowledged that youth were excluded in national health services and yet the youth experience ever increasing health problems. The ICPD also approved a plan of action which put much emphasis on integration of sexual and

\footnotetext{
*Correspondence Email: amuula@medcol.mw
} 
reproductive rights and universal access to reproductive health information and maternal health services. In trying to address the SRH challenges that the youth face, the Ministry of Health $(\mathrm{MoH})$ established youth friendly services in 2001 (Munthali, 2011). These services are supported by policies and characteristics of attracting youths to attend the facility or services, provide comfortable and appropriate setting for the youth to meet their needs and retain the youth, client follow up and repeated visits (Kamndaya et al., 2015a). The delivery points of these services are health facilities, community outlets such as youth clubs, Community Based Distribution Agents (CBDA) and HIV Testing and Counselling (HTC) sites.

Although Machinga district has youth clubs, the Machinga socio-economic profile for 2007-2011 showed that in primary schools many pupils drop out before reaching standard five (Machinga District Council, 2012). For example, in 2006 the district's socio-economic profile indicated that 8,197 pupils dropped out due to early marriages and poverty. In secondary school, 607 pupils also dropped out of school and out of these, $45.5 \%$ were boys and $54.5 \%$ were girls. From the 331 girls who dropped out of school 99 were due to pregnancy representing $30 \%$ of all drop outs (Machinga District Council, 2012). Machinga Health Management Information System (HMIS) also showed that $14 \%$ of the STI cases were among the adolescents and youths. Furthermore, the Machinga antenatal register showed that $20 \%$ of the pregnant mothers attending the services are youthw ranging from 15 to 24 years of age (Machinga Health Management Information Systems, 2012). This makes them prone to birth complications such as vaginal fistula and maternal death during labour and delivery (Yeakey et al., 2009; Kalilani-Phiri et al., 2010). Youth clubs as one of the delivery points of youth friendly services have an important role to play in addressing the SRH challenges that the young people face.

This study was carried out to assess the contribution of youth clubs towards promotion of sexual and reproductive health services among adolescents in southern Malawi. Specifically, we aimed to identify the services offered by youth clubs in promotion of youth reproductive health services; determine the use of SRH services among the youth; and determine the knowledge gained from youth clubs on SRH.

\section{Materials and Methods}

\section{Study design and setting}

This study was conducted in Machinga district in southern Malawi. We used a cross sectional study design incorporating both qualitative and quantitative methods. The study population were young people aged 15 to 24 years from Liwonde Township and the rest of the district. The study participants were residents of Machinga district who had stayed in the district for a minimum of a year. From Liwonde township (which is part of the district) participant drawn were those who attended the youth club at least once a month for a minimum of one year. The Machinga boma participants were those who have never attended youth clubs.

\section{Sample size and selection}

The calculated study sample size for the quantitative arm of the study was 180 including $10 \%$ refusal rate. However only 177 study youths accepted to participate in this study. We used stratified sampling method to select participants. The strata were based on youth club attendance and non-attendance. There were 10 youth clubs under Youth ImpactOrganisation. A sample of three youth clubs was drawn using random sampling. Systematic random sampling was used to draw participants from the youth club. Every second youth who attended the meeting at the youth club was selected into the study. However, only youths who met the inclusion criteria were included in the study and 90 youths were enrolled into the study.

For the qualitative study 90 study participants were drawn using systematic random sampling. The Health Surveillance Assistant (HSA) from Machinga health centre mobilised the youths for the meeting at the health facility. At the meeting every second youth was selected 
into the study. However, only youths who met the inclusion criteria were included in the study. The purposive sampling method was used to draw key informants and focus group members.

\section{Data collection}

We collected data through questionnaires for the quantitative data, and Focus Group Discussions (FGD) and key informant interviews using interviews guides. Four FGDs, two for females and the other two for males were conducted, two in each stratum. Four key informants were interviewed, two service providers from Machinga District hospital and two from Youth Impact organisation.

\section{Data analysis}

The quantitative data was analysed using Epi Info version 7. Categorical variables were compared using Chi-square test statistic at 5\% significant level. Qualitative data was analysed manually using thematic content analysis. The data was transcribed, themes identified, codes developed and categorised similar themes accordingly.

\section{Ethical considerations}

The study proposal was submitted to, reviewed and approved by the University of Malawi's College of Medicine Research and Ethics Committee (COMREC). The Machinga District Commissioner, Machinga District Health Officer and Youth Impact Organisation Director granted permission to conduct the study. Oral and written consents were obtained before the participants were enrolled into the study. Key informant interviews were done in their respective offices. The questionnaires used codes in order not to identify the study participants. The FGDs were conducted in a quiet place where non participants were unable to hear the conversation.

\section{Results}

\section{Characteristics of the sample}

A total of 177 youths participated in the study in the quantitative arm of the study, 50 (28.2\%) males and 39 (22.0\%) females from youth club attendees and $43(24.3 \%)$ males and $45(25.4 \%)$ females from non-attendees respectively. The study achieved $98.3 \%$ response rate. Most (129) of the study participants reported being sexually active). Out of these sexually active youths 70 (54.3\%) were youth club attendees and $59(45.7 \%)$ were non-attendees. Out of 177 study participants 144 (81.4\%) were single and $33(18.6 \%)$ were married. The study participants' level of education were secondary $63.8 \%$, primary $28.8 \%$, tertiary $6.2 \%$ and none $1.1 \%$. Three youth clubs namely, Youth Impact, Atikumbuchile and Simatheloamoyo were involved in the study.

\section{Services offered by the youth clubs}

We asked study participants what components of youth friendly reporiductive health services were provided at the clubs. The findings are reported in Table 2 below. Youth friendly services offered include contraceptive services, HIV counselling and testing and referral. However, HIV Counseling and testing were not available at Atikumbuchile and Simatheloamoyo. The frequency of services at the youth centres area summarised in Table 1.

Some $48.4 \%$ of the study participants reported that services offered were on HIV and AIDS education, $16.7 \%$ STI education and Family Planning each, Life skills $9.7 \%$ and $8.7 \%$ sporting activities (Table 1). Describing the services, participants had the following to say: 'We provide referral services for those who are positive, we are linked with the hospital people and they are two facilities that we are connected to, Machinga hospital and Gawanani health centre (Participant K1). We also provide free condoms to youth and education on how to use them'. The participants then added: 'Most of the times service provision in youth clubs are done by the members themselves and limits information dissemination'. Participants $\mathrm{K} 2$ had these to say: 'Health services provided at 
Youth Impact Organisation include awareness campaigns on SRH and straight talk in primary and secondary schools'. Another participant, added: 'We prefer to go to BLM or private clinics for STI treatment because of confidentiality issues and waiting time at public health facility' (Participant B5).

Table 1: Frequency of services mentioned as offered by youth club

\begin{tabular}{llcc}
\hline Services mentioned & Frequency & Percentage & Cumulative percentage \\
\hline HIV and AIDS Education & 61 & 48.4 & 48.4 \\
STI Education & 21 & 16.7 & 65.1 \\
FP & 21 & 16.7 & 81.8 \\
Life Skills & 12 & 9.7 & 91.5 \\
Sporting activity & 11 & 8.7 & 100.00 \\
Total & 126 & 100.00 & 100.00 \\
\hline
\end{tabular}

\section{Service utilisation among the youth}

The youth who utilised HTC services at Youth Impact Organisation were 124 (70.0\%) both attendees and non-attendees. Among those who attend youth clubs, 64 (51.6\%) were tested while 60 (48.4\%) non-attendees were also tested. The results showed that there was no association in youth club attendance and utilisation HTC. As regards to HTC, the participants had these to say: Participants A2 'For the HTC services we usually go to Youth Impact office because they have a youthful counsellor' while Participant K1 said: 'We are raising awareness through a number of strategies on HIV and AIDS and mostly we focus on prevention'.

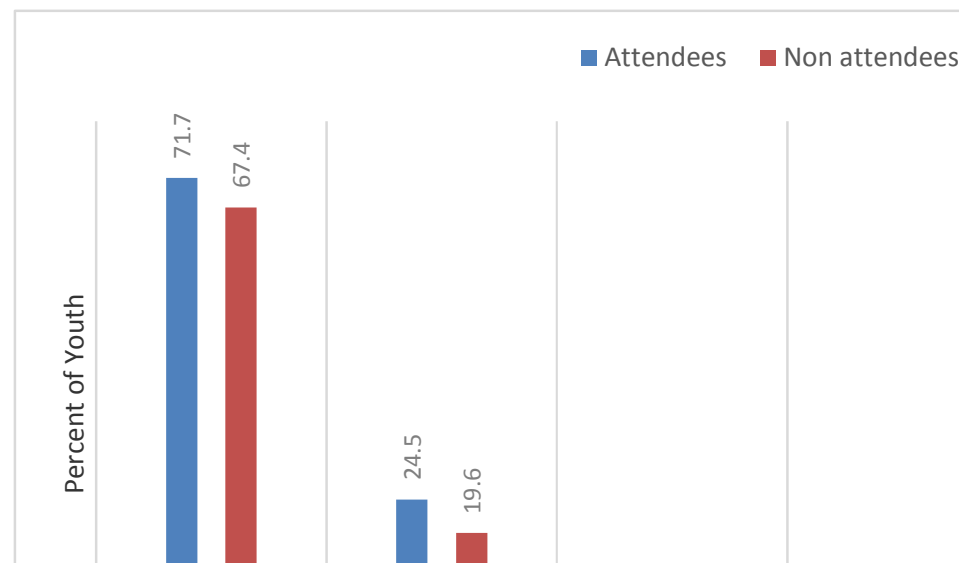

Figure 1: Percent distribution of contraceptive use among the youths (Chi-square value $=1.3, p=0.3$ )

Contraceptive use was higher among attendees than non-attendees (Figure 1). The results showed that there is no association in youth clubs attendance and contraceptive use. The results revealed that both youth club members and non-members use condoms (especially male condoms) as their family planning method $71.7 \%$ versus $67.4 \%$ and $24.5 \%$ versus $19.6 \%$ respectively followed by depoprovera and pills. We also found that youth who didnot attend youth club also used other family planning methods such as norplant, loop and the natural method. The youth who reportedusingnorplant, loop and natural method were from amongst the married people (Table 2). The following were some of the responses from the participants: 'It is easy to access condoms because they are readily available in shops' (Participant A4). Participant B3: 'Condom distribution is the most provided service'. Participant A2: 'It is better to use a condom than to let your partner use depoprovera because it reduces sexual drive (libido). Participant D6: 'Female condoms are too big, like a pale and they produce irritating noise during sexual intercourse which reduces sexual pleasure'. 'We use condoms because pills cause abdominal masses' (Participant D4). 
Table 2: Marital Status of youth and family planning methods

\begin{tabular}{lccc}
\hline FP method used & $\begin{array}{l}\text { Marital status } \\
\text { Married }\end{array}$ & Single & Total \\
\hline Condom & 9 & 59 & 68 \\
Depo & 12 & 7 & 19 \\
Norplant & 3 & 0 & 3 \\
None & 6 & 76 & 82 \\
Pills & 1 & 2 & 3 \\
Loop & 1 & 0 & 1 \\
Natural & 1 & 0 & 1 \\
Total & 33 & 144 & 177 \\
\hline
\end{tabular}

Most of the youths who used condom were single (86.8\%) than married youths (13.2\%). The use of depoprovera was common among the married youths (63.2\%) than among the single (36.8\%).

\section{Knowledge on SRH service}

There is strong association in youth club attendance and SRH knowledge. We found that of 177 study participants $71.2 \%$ had knowledge on $\mathrm{SRH}, 100 \%$ of the youth club attendees had knowledge on SRH and only 29.4 of youth club non-attendees did not have knowledge on SRH (Table 3). Some of the responses from the participants were: Participants A1: 'We learn ways of STI prevention including HIV and AIDS and the importance of HIV testing'. Participant B7: 'We discuss issues on prevention of HIV and AIDS and family planning methods'. Participant A9: 'Most of the times service providers from Youth Impact Organisation and health workers do not come to our clubs, we mostly teach one other'.

Table 3: distribution of youth who have knowledge on SRH

\begin{tabular}{llll}
\hline SRH Knowledge & Youth club attendees & Non attendees & Total \\
\hline With* & 89 & 37 & 126 \\
Without & 0 & 51 & 51 \\
Total & 89 & 88 & 177 \\
\hline Chi square value=69.1, $\mathrm{p}=0.000 . *$ =Those able to mention the following services STIs, HIV and AIDS, and \\
HTC
\end{tabular}

Table 4: Distribution of knowledge on FP methods

\begin{tabular}{llll}
\hline FP Knowledge & Youth club attendees & Non-attendees & Total (\%) \\
\hline Condom & 38 & 31 & 69 \\
Depo & 13 & 9 & 22 \\
Norplant & 0 & 3 & 3 \\
Pills & 2 & 1 & 3 \\
Loop & 0 & 1 & 1 \\
Natural method & 0 & 1 & 1 \\
Total & 53 & 46 & 99 \\
Missing & 36 & 42 & 78 \\
\hline
\end{tabular}

$*=$ Had no knowledge of FP

We also found that non-members have knowledge on other family planning methods such as norplant and natural method (Table 4). 


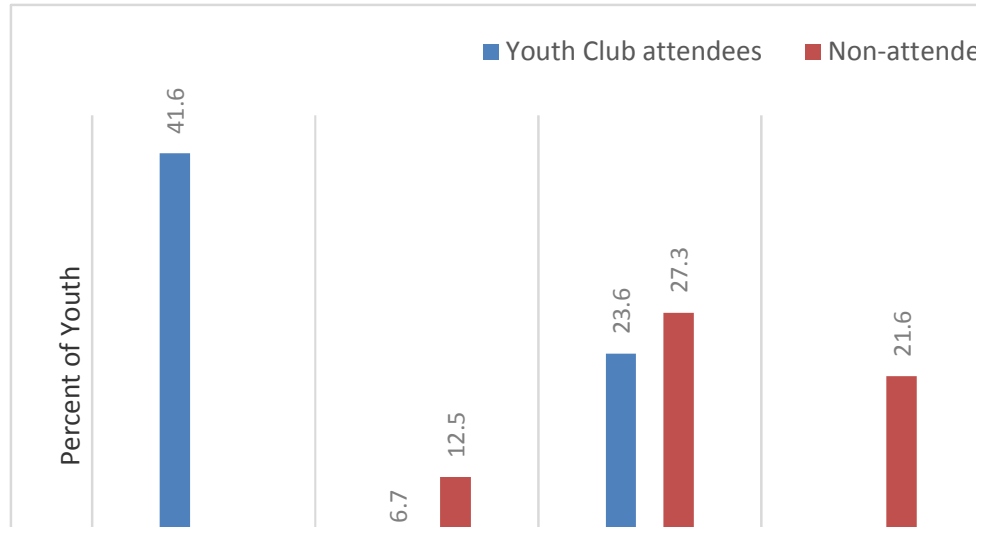

Figure 2: Percent of source of family planning information

We found that many of the youth club attendees got information on FP from clubs (41.6\%), health facility (25.8\%) and radio (23.6\%). Most of the non-youth club attendees got FP information from health facility (30.7\%), radio (27.3\%) and 21.6 had no knowledge of FP (Figure 2 ).

\section{Services provided by health workers}

The following are responses for some of the key informants regarding the services provided by health workers to the youths. Participant K3; 'We offer HIV and AIDS education sessions, conduct condom distribution and awareness campaigns in conjunction with Youth Impact Organisation. Participant K4: "Every Saturday we conduct a teen session on ART, FP, ANC and STI. The most patronised services is ANC. At FP clinic patronage is low due to attitude of some providers".

\section{Discussion}

Most of the youths reported being sexually active. If this sex occurs unprotected, this means that the youths are at risk of acquiring STI, HIV and unintended pregnancies and hence the need of SRH services. The study further showed that percentage of married youths who attend youth clubs was low. The low patronage may be due to the fact that many people view that youth clubs are services meant for people who are single. A greater percentage of the respondents were the youths at secondary school level. Primary school pupils are younger and therefore perhaps perceived or perceive that they may not need the services of youth clubs.

We found some gaps in provision of services at Atikumbuchire and Simathero youth clubs in terms of HTC services. This can be attributed to lack of trained peer counsellors. We also found that youth clubs provided HIV and AIDS education, followed by STI and FP method especially condoms. This shows that youth clubs attendees are provided with more HIV and AIDS information than other SHR services. These findings concur with other studies done elsewhere that most facilities offer services such as contraceptives, education, counselling and treatment of STIs, HIV and AIDS education (Kamndaya et al., 2015a,b). The key informant interviews further showed that most of the times the youth clubs conduct these services on their own without properly trained providers as most of the times health workers and Youth Impact peer educator do not come. The study also showed that there is low utilisation of other services such as FP methods.

We found that there was no association between youth club attendance and utilisation of services in terms of HTC. Adolescents and young people who attended clubs just as much accessed services as those who did not attend the clubs. We found that more youth went for HTC. These results are similar with the findings of Mwandira (2008) which showed that youth went for HCT despite the site of offering the services. This can be attributed to annual HCT campaigns conducted by the Ministry of Health, Stay Negative campaign shows done with 
support from Youth Impact, education in schools and communities on HIV prevention and door to door HCT campaigns. In theFGDs, we found most of the youths preferred to be tested by providers who do not know them. Therefore, campaigns that are conducted in Machinga give the youths an opportunity to be tested by unknown providers. Another study by Munthali et al. (2006) in Malawi reported that youths were not tested due lack of VCT services in the communities. The study had reported that availability of HCT sites in the community increase HCT services among the youths.

Most youth clubs attendees and non-attendees used condom as a method of FP, followed by depo. FGDs done with male participants revealed that they prefer to use condoms than their partners using depo because condoms are easy to access and depo reduce sexual drive in them (libido). FGDs done with females further revealed that they preferred condoms and depo than pills because the pills were thought to cause abdominal masses. These results slightly differ with the findings from a study conducted in Mangochi where female participants reported that pills clot in the intestines and uterus and subsequently the organs rot (Chipeta et al., 2009). Although, there is high use of condoms in most of the countries, there are differences in use of other types of family planning methods. For example, in Uganda among the sexually active people condom was the most used method followed by depo (Joseph, 2012; Kayongo, 2012). In Nigeria, a larger proportion of of sexually active students were reported having used condoms followed by abstinence and pills (Amazigo et al., 1997). The findings showed that accessibility and misconception affect the use of some of types FP methods.

We found that the youths had knowledge on SRH. The youth club attendees were more knowledgeable on SRH than non-attendees. This could be attributed to HIV and AIDS education sessions that Youth Impact conduct in their youth clubs. Most of the youths who were enrolled were school going individuals and the current school curriculum includes life skills as one of the subjects which covers reproductive health issues. These results concur with findings of a recent study by Kumwenda et al. (2011). Munthali et al. (2011) recently reported that knowledge of HIV and AIDS among Malawian adolescents is universal. This is contrary to the findings in this study which revealed that SRH knowledge is higher among youths who attend youth clubs. However these findings cannot be generalised because this study was conducted in clubs that are under Youth Impact and within 5 kilometres from Liwonde trading centre. Therefore, this showed that education sessions conducted in youth clubs increase knowledge among youths in Machinga.

We found that most youths enrolled had more knowledge on condoms as a family planning method. Among the sexually active youth in the study a larger proportion had knowledge on condoms. The high knowledge on condoms may be attributed to awareness campaigns conducted in the communities where both youth club attendees and non-attendees patronise. Findings from the FGDs also revealed that the National AIDS Commission (NAC) had facilitated several education sessions on condom use. The study revealed that awareness campaigns on condom use increase knowledge on condoms.

There was disparity in FP knowledge among youth club attendees and non-attendees. All Youth Club attendees had knowledge on FP and the majority got the information from the youth clubs. Apparently, other major sources of FP information for both attendees and non-attendees were health facilities and radios. This can be attributed to mass media awareness campaigns facilitated by the Ministry of Health and Non-Governmental Organizations on different methods of contraception available in Malawi. This is partly in line with another study by Munthali et al. (2004). These results are also slightly similar to the findings revealed by Botha (2010) where the major source of knowledge was from health workers, parents and peers to the adolescents. These results therefore suggest that the effectiveness of health workers and radios on dissemination of FP information was not different from both attendees and non-attendees. This further confirms the importance of the youth clubs as it provides useful family planning information to the youths. 
The results of this study revealed that health workers mostly provide HIV and AIDS including anti-retroviral therapy (ART) services. The key informant interview showed that during teen clinics, most of the youths attend ART and ante-natal clinic (ANC) and there is low turn up at Family Planning clinic. The FGD further revealed that the low turn up at FP clinic is due to negative attitude of some providers towards youth seeking the FP methods. These findings are slightly similar with those of a study in Kenya where the health providers perceived adolescents as uncooperative, arrogant, difficult to deal with, unwilling to be guided, uncompromising, secretive, and opposed to guidance and advice from adults (Kamau, 2006). This indicates that a good relationship between youths and health workers is important in determining youth access and utilisation of SRH services.

We found that the attitude of health workers affects accessibility of FP services to the youths. Similar findings have been reported from a study in Kenya where the health providers perceived adolescents as uncooperative, arrogant, difficult to deal with, and opposed to guidance and advice from adults (Kamau, 2006). The negative attitude towards the youth seeking FP methods can be attributed to inadequate number of trained YFHS providers. Negative attitude towards female condoms also affected accessibility of the method as most youth felt that female condoms reduce sexual pleasure. This can be attributed to inadequate awareness campaigns on female condoms. The results further revealed that HTC and condom distribution were the most services provided by the health workers.

This study several limitation. We depended on individual reports which is subject to recall bias and social desirability on sensitive issues pertaining to sexual and reproductive health. The sample size, especially for the quantitative arm of this study was small thereby affecting the precision of estimates. The study results cannot therefore be generalised to the whole country.

In conclusion, we confirm that youth clubs contribute in the promotion of SRH in terms of knowledge and a major source of FP information. In view of the study findings, we recommend the following: (i) Youth Impact and the existing youth club members should mobilise youth to join the clubs and consider creating new clubs in areas where they do not exist; (ii) Machinga DHO should consider training peer educators and counselors from youth clubs to ensure provision of accurate information on SRH and HTC services; (iii) Machinga DHO and Youth Impact should increase awareness of female condoms and other FP methods such as depoprovera and pills; (iv) Youth Impact should provide support to the existing youth clubs in Machinga; and (v) Machinga DHO and Youth Impact should provide supportive supervision to the youth clubs for them to be actively involved in SRH services.

\section{Acknowledgements}

We thank the study participants for their contributions to the study.

\section{References}

Amazigo, U., Silva, N., Kaufman, J., Obikeze, D.S. (1997) Sexual Activity and contraceptive knowledge and use among in-school Adolescent in Nigeria. Accessed on $28^{\text {th }}$ April, 2014 www.guttmacher.com/pubs/journals/2302897.pdf

Botha, S.J. (2010) An investigation into adolescent's access to family planning services and reproductive health information in Lilongwe district. Accessed on $6^{\text {th }}$ May www.medcol.mw/commhealth/mph/dissertations/Botha_Janet_Dissertation 230810\%20F inale.pf

Chipeta, E.K., Chimwaza, W. \& Kalilani-Phiri, L. (2010) Contraceptive Knowledge, Beliefs and Attitudes in Rural Malawi: Misinformation, Misbeliefs and Misperceptions. Malawi Medical Journal 22, 38-41. 
Joseph, J.E. (2012) Utilisation of Family Planning Services Among Sexually Active People Living With HIV/AIDS in TASO TORORO. Accessed on $6^{\text {th }}$ May, 2014 http://news.Mak.ac.ug/documents/Makfiles/thesis/Egessa\%20john\%2ojoseph.pdf

Kalilani-Phiri, L.V., Umar, E., Lazaro, D., Lunguzi, J. \& Chilungo, A. (2010) Prevalence of obstetric fistula in Malawi. International Journal of Gynaecology and Obstetrics 109, 204-208.

Kamau, A.W. (2006) Factors influencing access and utilisation of preventive reproductive health services by adolescents in Kenya. A case study of Murang'a district. PhD thesis. Beilefeld University, Germany. Accessed on $4^{\text {th }}$ May, 2014. http://pub.unibielefeld.de/luur/download?func=downloadFile\&recordOId=2305119\&fileOld=2305122

Kamndaya, M., Kazembe, L.N., Vearey, J., Kabiru, C.W. \& Thomas, L. (2015a) Material deprivation and unemployment affect coercive sex among young people in the urban slums of Blantyre, Malawi: A multi-level approach. Health Place 33, 90-100.

Kamndaya, M., Vearey, J., Thomas, L., Kabiru, C.W. \& Kazembe, L.N. (2015b) The role of material deprivation and consumerism in the decisions to engage in transactional sex among young people in the urban slums of Blantyre, Malawi. Global Public Health 5:1-14.

Kayongo, S.B. (2013) Uptake of Morden Contraception among Youth 15 - 24 at Community Level in Busia District Uganda. Makerere University, Accessed on $28^{\text {th }}$ April, 2014 www.musphcdc.ac.ug/files/pdf/uptakeofmordencontraceptionamongyouth1524atcommunitylevelinBusiadistrict,ugandabysuzababirye.pdf

Kidman, R. \& Anglewicz, P. (2014)_Fertility among orphans in rural Malawi: challenging common assumptions about risk and mechanisms. International Perspectives on Sexual and Reprouctive Health 40, 164-175.

Kumwenda, S., Kambala, C., Mwendera, C. \& Kalulu, K. (2011) What do Malawi Polytechnic first years students know and do about HIV and AIDS? Malawi Medical Journal 23, 6-10.

Machinga District Council (2012) Machinga Socio-economic Profilezo07 - 2012 Machinga Malawi.

Munthali, W.K. (2011) Evaluation of youth friendly reproductive health services for adolescents aged 14-19 years in Lunzu T/A Kapeni, Blantyre. Accessed on $6^{\text {th }}$ May, 2014 www.medcol.mw/commhealth/mph/dissertations/Wezzie\%20Munthali.pdf.

Munthali, A.C., Chimbiri, A. \& Zulu E. (2004) A report on Adolescents Sexual and Reproductive Health in Malawi: A Synthesis of Research Evidence the Allan Guttmacher Institute, New York, Washington. Accessed on $6^{\text {th }}$ June, 2013 http://www.guttmacher.org/pubs/2004/12/01/or_no15.pdf

Munthali, A., Zulu, M.E., Madise, N., Moore, A.M., Kanyoni, S., Kaphuka, J. \& Banda, D.M. (2006) Adolescent Sexual and Reproductive Health in Malawi: Results from the 2004 National Survey of Adolescent Occasional Report No 24. Accessed on $7^{\text {th }}$ May. 2014 www.guttmacher.org/pubs/2006/07/25/or24.pdf.

Mwandira, J.H.G. (2008) A Comparative Study of Effectiveness of Youth Peer HCT Counsellors and Adult Counsellors (Health workers) in Promoting Uptake of HIV Counselling and Testing among the Youth in Lilongwe. Accessed on $29^{\text {th }}$ April, 2014 www.medcol.mw/commhealth/mph/dessertations/jeanmwandira.pdf

Senderowitz, J., Hainsworth, G. \& Solter, C. (2003) A Rapid Assessment of Youth Friendly Reproductive Health Services. Pathfinder International No. 4. Accessed on $27^{\text {th }}$ July,2013 http://www2.pathfinder.org/site/docserver/\%20\%20yfs_tg_final_web_version.pdf?docid=7 62

Wentzell, E.A. \& Inhorn, M.C. (2014) Reconceiving masculinity and 'men as partners' for ICPD Beyond 2014: insights from a Mexican HPV study. Global Public Health 9, 691-705.

Yeakey, M.P., Chipeta, E., Taulo, F. \& Tsui, A.O. (2009) The lived experience of Malawian women with obstetric fistula. Culture, Health and Sexuality 11, 499-513. 